\title{
The great American dream machine runs out of fuel
}

\section{David Dickson discusses the dilemmas facing the Carter administration over the future shape of the US space effort}

$F^{\text {IRST the good news. President }}$ Carter's administration has proposed that the space science budget of the National Aeronautics and Space Administration (NASA) be increased. by $26.7 \%$ to a record level of $\$ 513 \mathrm{mil}-$ lion-out of a total NASA budget of $\$ 3,305$ million-in 1979.

Now the bad. There are no plans to start any new planetary missions in 1979 , and it now appears that apart from Project Galileo, the Jupiter Orbiter/Probe given the go-ahead by Congress last year, no major new planetary programme is likely to be under way until the mid-1980s.

It is almost exactly 20 years since the US entered the space race with the launch of the Explorer satellite from Cape Canaveral on 30 January, 1958 as a hastily arranged response to the trauma of being beaten into space by the Russian Sputnik. It is also the 20th anniversary of the National Aeronautics and Space Act of 1958, which established NASA. And last week, in celebration of the latter event, the Senate Committee on Commerce, Science and Transportation held a symposium on the future of space science and space technology.

If the future facing space science 20 years ago lay full of hope and promise, the symposium indicated how confused and uncertain the picture is today. This confusion is reflected in doubts about the future directions that NASA should pursue, indeed doubts about the whole shape of the US space effort, including space science.

Two areas are doing well. The first is space astronomy, with exciting results on X-ray and gamma-ray emission already coming from the High Energy Astronomical Observatory (HEAO), launched last year, and more promised from the Large Space Telescope, which is being started in the 1978 budget. The second area which is also expanding, and which reflects the administration's desire to see an emphasis placed on the basic research necessary to support applied research, lies in the area of space applications. Here the relative complexity of some new applications of satellite technology, such as earth reresources reconnaissance and climatology, at least in comparison to earlier applications such as telecommunications, have given rise to a significant increase in the supporting science.
But there are two areas in which current frustrations are running high, and short-term expectations-in spite of vigorous pressure-remain low. The first is in what has been called "space industrialisation", where the imagination of space engineers, with plans for mining asteroids for important minerals and creating vast solar receptors to beam energy down to earth, have so far not been matched by any major commitment from NASA. The agency claims that it is holding back work on large space structures until it sees the outcome of the Space Shuttle programme.

\section{Planetary science}

Planetary science is the second area in which NASA appears to be holding back from any major future commitment. Admittedly the present situation for planetary science is not too bad, largely because of the success of scientists in getting the Jupiter Orbiter/ Probe into the 1978 budget. (Indeed, the main reason for the substantial $26.7 \%$ increase in the 1979 space science budget is last year's acceptance by Congress of this and the space telescope, both projects requiring substantially more funding in the second rather than the first year).

But the Jupiter project only survived in NASA's programme after a considerable battle in Congress, which required mustering the full letter-writing potential of the planetary science community. Although accepted by the Senate, the project was rejected in a surprise move by the House Appropriations Committee under the chairmanship of Mr Edward Boland (DemMass), and only scraped through following compromises made at the conference stage.

Less fortunate has been a proposed project to send a spacecraft into a polar orbit around the Moon, making use of a set of matched sensors that would have provided a survey of the whole planet from a height of $100 \mathrm{~km}$. This had been proposed within NASA in three successive years, and twice (for 1978 and 1979) put forward by NASA to the Office of Management and Budget, only to be rejected on each occasion. It now seems unlikely that NASA will be prepared to put forward this project again, preferring to rethink how it should reapproach the
Moon at a later date, possibly in five or ten years' time.

Two other projects discussed within NASA failed to get the agency's support. The first was the proposal to send a spacecraft to rendezvous with $\mathrm{Hal}-$ ley's Comet, due to make its once-in75-years approach to the sun in 1986. A second project was a proposed follow-up to the Viking mission to Mars, either sending a roving vehicle to the planet to gather more information about its surface, or to arrange for a sample of Mars rock to be brought back to earth for analysis.

The possibility of a Mars project is still receiving enthusiastic backing from scientists, particularly those interested in investigating the distribution of organic matter in the universe. And there will be a considerable push this year to get a trip to Mars in 1986-the next date when the planet will be in a suitable position relative to the Earth-into the 1980 budget.

However, it will have to compete with another equally attractive proposal, that to send an imaging radar device to orbit Venus in order to make the first accurate measurements of the planet's surface through its dense clouds. A Venus project could be particularly attractive for two reasons. Firstly, there are already two planned Pioneer trips to Venus planned for launching in May and August of this year, and interest in the planet is therefore likely to be high. Secondly, and perhaps politically more important, is the fact that the Russians are planning both a fly-by mission, probably with an orbiter, and also a joint mission with the French that will involve dropping a balloon into the planet's atmosphere.

Apart from these there are a number of additional projects being proposed, each with its group of supporters. One is to send a mission to Titan, the largest of Saturn's moons, whose atmospheric conditions make it of particular interest to space scientists with biological interests. Those disappointed by the failure to gain support for a mission to Halley's Comet still contend that a comet mission of some kind would provide invaluable information about the origins of the universe. And there is also a project being discussed to reintroduce manned investigation in the relatively near future with a mission to one of the many small bodies, such as the nuclei of burnt-out comets, that orbit the Sun close to the Earth.

Each of these projects would be fruitful from both a scientific and a technological point of view. The main problem facing planetary scientists, however, is how to secure that extra bit of commitment from the administration necessary to obtain the vast amount of resources that each would require. 


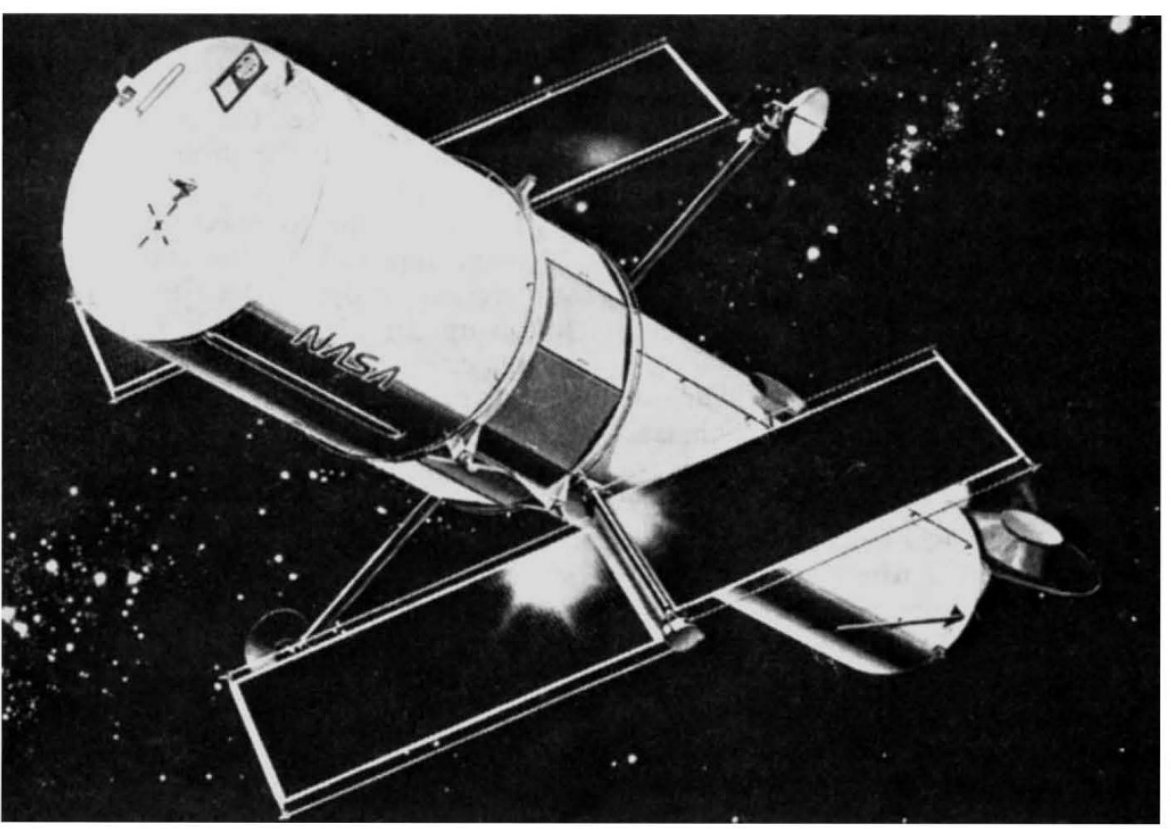

Artists' impression of NASA's space telescope

\section{Victims of earlier success}

The size of the projects, the uncertainties involved, and the long-term nature of any pay-off, make it impossible to apply with any degree of accuracy the type of cost-benefit analysis that is increasingly being required of $R \& D$ efforts. As Dr Noel Hinners, associate administrator for space science at NASA, points out, "scientists have desires, not requirements."

But in their failure so far to gain the necessary backing, the hawks of both space technology and space science are partially the victims of their own earlier success. On the one hand, the apparent ease with which the space bonanzas of the $1960 \mathrm{~s}$ were achieved, and the technological euphoria which they generated, has obscured the type of commitment needed to secure success; recent launcher failures and technical problems with Space Shuttle engines have made both administrators and politicians more cautious in their projections of feasibility.

The second spin-off from earlier successes has been that, by putting the emphasis on the more competitive aspects of getting places first, it has been made comparably harder to argue for follow-up missions of equal, if not greater, scientific value. Both the proposed lunar and Mars projects which failed to receive funding for 1979 suffered partially from this problem.

The resulting situation was expressed at the Senate symposium by Professor James Arnold, of the Department of Chemistry at California University, La Jolla, and a leading advocate of the lunar mission. "The lunar and planetary science community currently feels a great frustration based on the paradox that we have very exciting things that we know how to do, but budgetary restrictions on doing them," he said.

This frustration, shared with those who would like to see NASA advancing rapidly into large technological structures, finds a frequent echo in Congress from those who argue the need for the US to maintain a position of superiority both in leading the pursuit of new knowledge, and in maintaining a technological advantage over other nations (NASA's formal role is according to the National Space Act to preserve the role of the US "as a leader in aeronautical and space science and technology").

But this style of political debate, however attractive it may have appeared during the Cold War period when politicians could play on the fear of Soviet technological superiority, is out of place in the current administration. The form of hegemony that President Carter sells is moral, rather than technological (just as the success of Star Wars is based less, as the space hawks like to suggest, on the inherent attractions of space travel as on the apparent victory of morality over technology).

Thus, however much he is attacked for showing a lack of imagination, space bonanzas, whether scientific or technological, are not Carter's style; like other candidates for federal aid, they require pragmatic justification, in the way that NASA is putting increasing emphasis on the "useful applications" of space technology-and the science necessary to achicve it-rather than the more glamorous aspects.

Dr Robert A. Frosch, NASA's newly appointed director, is under pressure from both Congress and the aerospace industry to take a more "imaginative" approach. But he is proceeding cau- tiously, and as a result finds himself "in the somewhat paradoxical situation that as steward of NASA I have been cast in the role of the conservative, a brand new position for both me and the agency."

\section{Looking to the future}

As the NASA budget for 1979 comes under scrutiny from Congress, there are likely to be several attempts to increase both its size and its scope. Already Representative Olin Teague, for example, has been persuaded to table a resolution pressing the investigation of space resources. And representative Ronnie G. Flippo of Alabama echoed a widely-held feeling when he told the House two weeks ago that the 1979 budget was in general "a status quo budget, lacking in the kind of action, boldness and innovation which should characterise scientific leadership."

But in general space is much lower on Congress' priority list than it was ten years ago. Pay-offs must not only be promised, but their feasibility demonstrated. The Space Shuttle, for example, succeeded in getting through Congress largely as a result of the economies that could be demonstrated for a re-usable space vehicle, and its potential commercial viability.

The changing environment is further reflected in the uncertainty over the future of NASA, itself partially a victim of its own success. Some claim that the agency should now shift its concern from the means to the goals of space activity, helping to build what one enthusiast calls "the new space America."

Others feel that NASA's responsibility should remain essentially exploratory and experimental, although most space scientists seem to agree that the agency should remain responsible for both the basic sciences and the investigation of its implications, since the former will only thrive if conducted in a symbiotic relationship with the latter.

At present the administration in general-and President Carter in particular - seem uncertain about the direction in which NASA should turn. A study of the national space effort conducted as a result of a presidential memorandum last year by Dr Norman Brown, Secretary of State for Defense, is said to have disappointed the administration in its conclusions.

More significant for space science will be a "public declaration" on the future shape of civil space activity, including NASA, which is currently being prepared by Dr Frank Press's Office of Science and Technology Policy. Some form of statement from OSTP is expected next month; but a renewed commitment to major programmes in space still seems a long way off. 